\title{
RIBOSOMAL DNA CONTENT AND BOBBED PHENOTYPE IN DROSOPHILA HYDEI
}

\author{
ULRICH SCHÄFER and WERNER KUNZ \\ Institut für Allgemeine Biologie, Universität Düsseldorf, D-4000 Düsseldorf, Germany \\ Received 12.iv.1976
}

\section{Summary}

The number of ribosomal RNA genes in different Drosophila hydei stocks has been determined by filter saturation hybridisation experiments. It has been shown that there is no marked correlation between the average rRNA gene number per cell in the whole animal and the bobbed phenotype when $\mathrm{Y}$ chromosomal nucleolar organisers are present.

\section{INTRODUCTION}

THE ribosomal RNA cistrons (rDNA) are clustered at the nucleolus organiser region (NO) (Ritossa and Spiegelman, 1965). In most of the Drosophila species, the NO's are localised on the sex chromosomes. In $D$. melanogaster it was shown that the NO is identical with the bobbed $(b b)$ locus since a

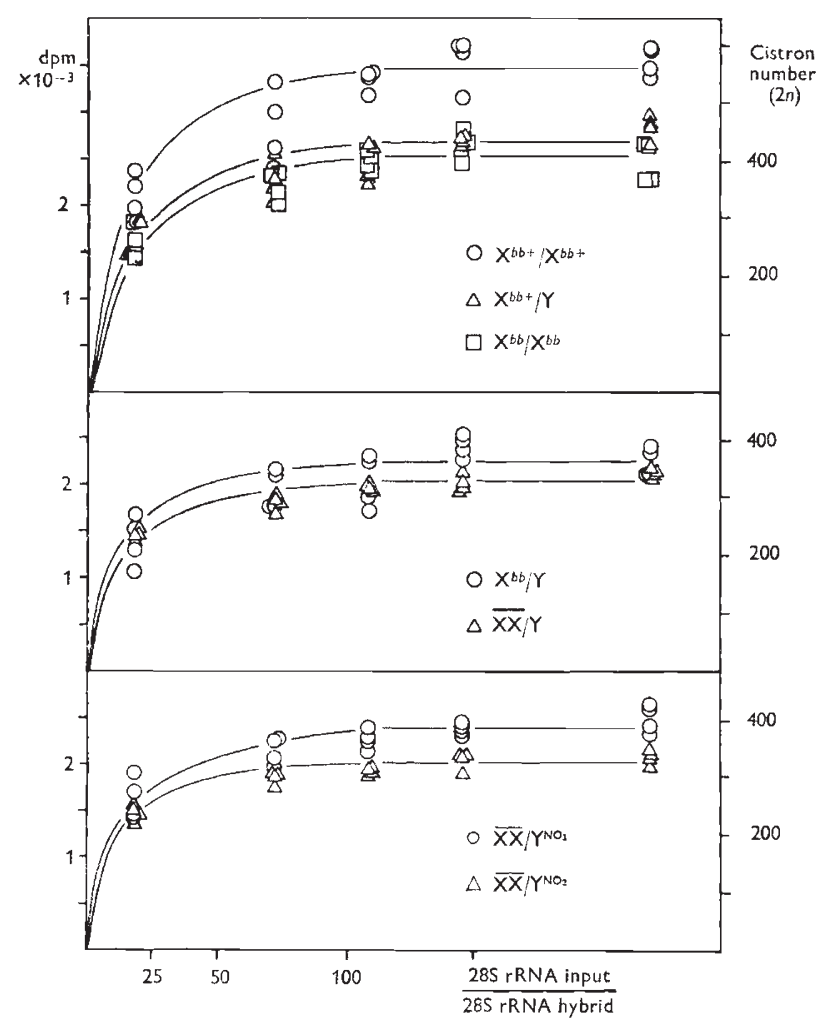

FIG. 1.-Saturation curves of DNA of different $D$, hydei stocks hybridised with $28 \mathrm{~S}$ rRNA. 
marked deficiency in rRNA genes is correlated with the $b b$ phenotype (short, thin bristles) (Ritossa, Atwood and Spiegelman, 1966). A phenotypically similar $b b$ mutation has been described in $D$. hydei (Clausen, 1923). In this species, the $\mathrm{X}$ chromosome has one NO while the $\mathrm{Y}$ has two separate NO's, one on the short arm $\left(\mathrm{NO}_{1}\right)$, the second near the tip of the long arm $\left(\mathrm{NO}_{2}\right)$ (Hennig, Link and Leoncini, 1975; Schäfer and Kunz, 1975). Since the attached-X $(\overline{\mathrm{XX}})$ chromosome used in our experiments lacks the NO containing heterochromatic arms, it is free of rDNA (Schäfer and Kunz, 1975; Kunz and Schäfer, 1976). A comparison of the total rDNA content of females and males shows that the ribosomal cistron number of the $\mathrm{Y}$ chromosome is smaller than that of the X (Hennig, 1968; Kunz and Schäfer, 1976; see also fig. 1). Therefore, genetic constitutions containing the $\overline{\mathrm{XX}}$ chromosome should have only small amounts of rDNA and are suitable for the study of the relation between the rDNA gene number of the $b b$ phenotype.

\section{Materials and methods}

(i) D. hydei stocks

Seven different genotypes were investigated.

(a) Females $\left(\mathrm{X}^{b b+} / \mathrm{X}^{b b+}\right)$ and males $\left(\mathrm{X}^{b b+} / \mathrm{Y}\right)$ from our laboratory wild type inbred stock.

(b) Females $\left(\mathrm{X}^{b b} / \mathrm{X}^{b b}\right)$ and males $\left(\mathrm{X}^{b b} / \mathrm{Y}\right)$ carrying a spontaneous $b b$ mutation.

(c) $\overline{\mathrm{XX}}$-females having either the whole $\mathrm{Y}$ chromosome $(\overline{\mathrm{XX}} / \mathrm{Y})$ of one of two reciprocal $\mathrm{Y}$ fragments $\left(\overline{\mathrm{XX}} / \mathrm{YNO}{ }_{1}\right.$ and $\overline{\mathrm{XX}} / \mathrm{YNO}_{2}$, respectively); for details of these stocks see Kunz and Schäfer (1976).

\section{(ii) Bristle index}

To quantify the $b b$ phenotype, we used the bristle index (B.I.) of Beck (1972) with a slight modification. B.I. is defined as the sum of the lengths of the two posterior scutellar setae divided by the distance between the two anterior scutellar setae. Twenty-five flies of each genotype were scored.

\section{(iii) $D N A-R \mathcal{N} A$ hybridisations}

DNA extraction, ${ }^{3} \mathrm{H}$ 28S rRNA purification, and filter hybridisations were carried out as previously described (Kunz and Schäfer, 1976) except for some alterations in the hybridisation conditions: 4 hours incubation at $60^{\circ} \mathrm{C}$ in 50 per cent formamide and $6 \times \mathrm{SSC}$. One DNA preparation was made for each genotype using whole adult flies, collected 1 to 3 days after emergence. Four different hybridisation experiments were carried out. In each of these experiments seven filters each loaded with the DNA of one genotype and two blank filters were incubated in varying arrangements within the same vial. The specific activity of the ${ }^{3} \mathrm{H} 28 \mathrm{~S}$ rRNA was $2 \cdot 5 \times 10^{5} \mathrm{dpm} / \mu \mathrm{g}$. For the calculation of the cistron numbers see Kunz and Schäfer (1976).

\section{Results}

The wild type female $\left(\mathrm{X}^{b b+} / \mathrm{X}^{b b+}\right)$ has a B.I. of $2 \cdot 70 \pm 0 \cdot 09$, our $\mathrm{X}^{b b} / \mathrm{X}^{b b}$ female a B.I. of $1.97 \pm 0.09$ (fig. 2). DNA-RNA filter saturation hybridisa- 
tions have shown that the $b b+$ female has $565 \pm 32$ rRNA cistrons whereas the homozygous $b b$ female has a significantly lower rRNA gene number $(411 \pm 27)$. Thus, according to expectation, the $b b$ phenotype in $D$. hydei, like that in $D$. melanogaster, is correlated with a lower rDNA content.

The wild type male $\left(\mathrm{X}^{b b+} / \mathrm{Y}\right)$ shows a bristle index which is clearly within the range of the wild phenotype $(2 \cdot 72 \pm 0 \cdot 05)$. Nevertheless, its rRNA gene number $(434 \pm 35)$ is as small as that of the $b b$ female.

The $\mathrm{X}^{b b} / \mathrm{Y}$ male has an rDNA content ( $365 \pm 39$ cistrons) which is similar to that of the $\mathrm{X}^{b b} / \mathrm{X}^{b b}$ female $(411 \pm 27)$, but in spite of this low rRNA gene number its bristle index is significantly higher $(2 \cdot 44 \pm 0 \cdot 11)$. The index is somewhat smaller than the wild type B.I. (fig. 2).

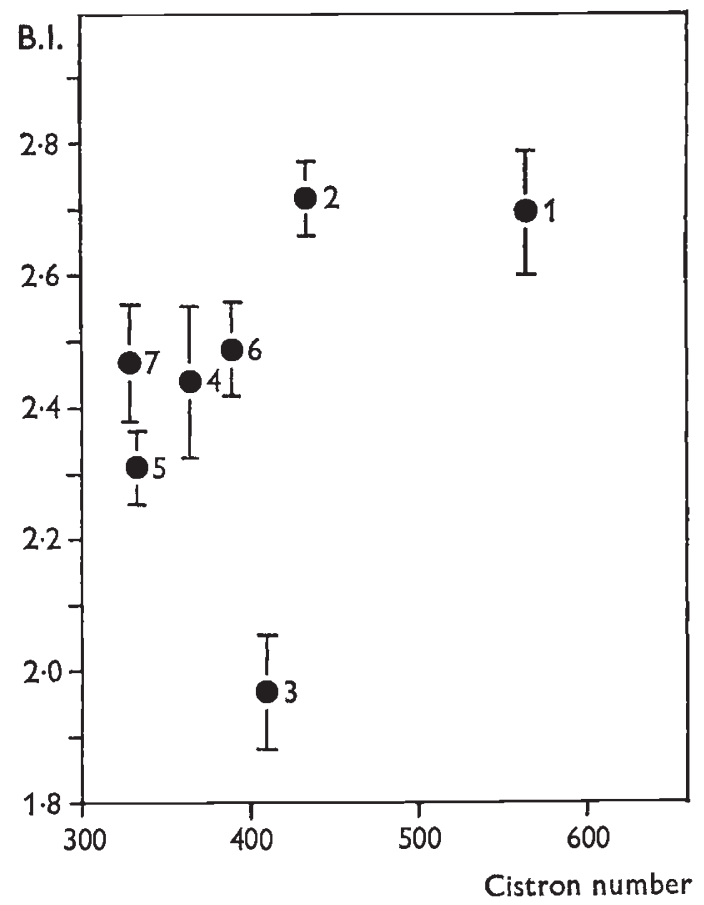

FIG. 2.-Plot of rRNA gene numbers relative to the bristle index. Genotypes:
(1) $\mathrm{X}^{b b+} / \mathrm{X}^{b b+}$; (2)
(2) $\mathrm{X}^{b b+} / \mathrm{Y}$;
(3) $\mathbf{X}^{b b} / \mathbf{X}^{b b}$;
(4) $\mathrm{X}^{b b} / \mathrm{Y}$;
(5) $\overline{\mathrm{XX}} / \mathrm{Y}$;
(6) $\overline{\mathrm{XX}} / \mathrm{Y}^{\mathrm{NO}}$;

(7) $\overline{\mathrm{XX}} / \mathrm{Y}^{\mathrm{NO}}$.

The $\overline{\mathrm{XX}} / \mathrm{Y}$ female should possess only the rRNA gene number of a single wild type $\mathrm{Y}$ chromosome (152) because it has no X chromosomal NO. Due to the so-called gene compensation mechanism (Tartof, 1973; Kunz and Schäfer, 1976), however, its gene number is higher (332 \pm 14$)$. Nevertheless, this is distinctly lower than the rDNA content of the $b b$ female. Yet, the bristle index $(2 \cdot 31 \pm 0 \cdot 06)$, as in the $\mathrm{X}^{b b} / \mathrm{Y}$ male, falls between the wild type and the $b b$ phenotype indices.

The rRNA gene numbers and bristle indices were also measured in two stocks where the $\overline{\mathrm{XX}}$ chromosome was combined with one half of a $\mathrm{Y}$. Therefore, each of these two genotypes contained only one of the two Y 
chromosomal NO's. Due to gene compensation, the rDNA contents of these stocks also are increased and were found to be $390 \pm 24$ and $329 \pm 16$ cistrons, respectively. These values, again, are not higher than the rRNA gene number of the $b b$ female but their bristle indices are significantly higher $(2 \cdot 49 \pm 0.07$ and $2 \cdot 47 \pm 0 \cdot 09)$.

\section{Discussion}

Our data show that in the investigated $D$. hydei genotypes with Y chromosomal NO's there was no marked correlation between the bristle index and the rRNA gene number (fig. 2). This indicates either that the NO's of the $\mathrm{Y}$ chromosome react differently from that of the $\mathrm{X}$ or that there exist other factors besides the amount of rDNA influencing the $b b$ expression. The latter conclusion is supported by the existence of an autosomal mutation which modifies the degree of bristle reduction in $b b$ stocks of $D$. hydei (Beck, 1975).

Similar to our results in $D$. hydei, in $D$. melanogaster recently a genetic constitution has been described which had wild type bristle length but a very low rRNA gene number (Shermoen and Kiefer, 1975). The authors presented data which showed a direct relationship between the rate of rRNA accumulation and bristle length. This is in accord with the previous observations of Weinmann (1972). Therefore, the factor which determines the $b b$ expression is possibly not the rRNA gene number but the rate of the rRNA synthesis. Another explanation could be that a specific degradation of the 28S rRNA causes the $b b$ phenotype in spite of a high rRNA gene number (Marrakechi, 1974).

Also, females of $D$. melanogaster which had increased their rDNA by gene magnification were still bobbed (Tartof, 1973). In this case, it has been suggested that the additional rDNA is not functional. In $D$. hydei the situation seems to be different since our three $\overline{\mathrm{XX}}$ genotypes with a high percentage of compensated rDNA did not show the $b b$ phenotype (fig. 2).

Our stocks where a low rDNA content was coupled with a relatively high bristle index, all contained intact NO's, whereas the $b b$ female having a similar rDNA content accompanied by a low bristle index has undergone a deletion in the NO region. This observation supports the hypothesis (Marrakechi and Prud'homme, 1971; Shermoen and Kiefer, 1975) that the rate of rRNA synthesis is controlled by special segments in the rDNA which may be inactivated due to deletion.

On the other hand, it has to be considered that our gene number determinations were carried out on the DNA extracted from whole animals whereas the bristle development is cell autonomous. Since it has been shown that different tissues may vary in the number of their ribosomal RNA genes (Hennig and Meer, 1971 ; Spear and Gall, 1973; Renkawitz and Kunz, 1975) a correlation between the bristle length and the rDNA content may still exist even in genotypes with Y chromosomal NO's but it may be restricted to the bristle forming cells.

Acknowledgment.-We thank Miss D. David, Mrs A. Gerber, and Miss M. Sticker for excellent technical assistance. This work was supported by the Deutsche Forschungsgemeinschaft (Ku 282/5). 


\section{REFERENCES}

BECK, H. 1972. The phenotype of $X^{b b+} / \mathrm{O}$ males in Drosophila hydei. Drosophila Inform. Serv. $49,76$.

ВECK, н. 1975. Zur Wirkung eines autosomalen Gens auf den bobbed-Phänotyp bei Drosophila hydei. Arch. Genetik, 48, 69.

Clalisen, R. E. 1923. Inheritance in Drosophila hydei. Amer. Nat., 57, 52-58.

HENNIG, w. 1968. Ribonucleic acid synthesis of the Y-chromosome of Drosophila hydei. 7. Mol. Biol., 38, 227-239.

HENNIG, W., LINK, B., AND LEONCINI, o. 1975. The location of the nucleolus organizer regions in Drosophila hydei. Chromosoma (Berl.), 51, 57-63.

HENNIG, W., AND MEER, B. 1971. Reduced polyteny of ribosomal RNA cistrons in giant chromosomes of Drosophila hydei. Nature New Biol., 233, 70-72.

KUNZ, W., AND SCHÄFER, U. 1976. Variations in the number of the Y chromosomal rRNA genes in Drosophila hydei. Genetics, 82, 25-34.

MARRAKECHI, м. 1974. Etude d'un mutant bobbed ayant une quantite-normale d'ADN ribosomal. Molec. Gen. Genet., 135, 213-229.

MARRAKECHI, M., AND PRUD'HOMME, N. 1971. A study of bobbed mutants induced by ethyl-methane-sulfonate in Drosophila melanogaster. Biochem. Biophys. Res. Commun., 43, 273-277.

RENKAWITZ, R., AND KUNZ, w. 1975. Independent replication of the ribosomal RNA genes in the polytrophic-meroistic ovaries of Calliphora erythrocephala, Drosophila hydei, and Sarcophaga barbata. Chromosoma (Berl.), 53, 131-140.

RitossA, F. M., ATwOOD, K. C., AND SPIEgElman, s. 1966. A molecular explanation of bobbed mutants of Drosophila as partial deficiencies of " ribosomal" DNA. Genetics, 54, 819-834.

RITOSSA, F. M., AND SPIEgELMAN, s. 1965. Localization of DNA complementary to ribosomal RNA in the nucleolus organizer regions of Drosophila melanogaster. Proc. Nat. Acad. Sci. (Wash.), 53, 737-745.

SCHÄFER, U., AND KUNZ, W. 1975. Two separated nucleolus organizers on the Drosophila hydei $\mathrm{Y}$ chromosome. Molec. Gen. Genet., 137, 365-368.

SHermoen, A. W., AND KIEFER, B. I. 1975. Regulation in rDNA-deficient Drosophila melanogaster. Cell, 4, 275-280.

SPEAR, B. B., AND GALL, J. G. 1973. Independent control of ribosomal gene replication in polytene chromosomes of Drosophila melanogaster. Proc. Nat. Acad. Sci. (Wash.), 70, 1359-1363.

TARTOF, K. D. 1973. Regulation of ribosomal RNA gene multiplicity in Drosophila melanogaster. Genetics, 73, 57-71.

WEINMANN, R. 1972. Regulation of ribosomal RNA and 5S RNA synthesis in Drosophila melanogaster. I. Bobbed mutations. Genetics, 72, 267-276. 